\title{
Objectified conformity: working self-objectification increases conforming behavior
}

\section{Luca Andrighetto, Cristina Baldissarri, Alessandro Gabbiadini, Alessandra Sacino, Roberta Rosa Valtorta \& Chiara Volpato}

To cite this article: Luca Andrighetto, Cristina Baldissarri, Alessandro Gabbiadini, Alessandra Sacino, Roberta Rosa Valtorta \& Chiara Volpato (2018): Objectified conformity: working selfobjectification increases conforming behavior, Social Influence

To link to this article: https://doi.org/10.1080/15534510.2018.1439769

$$
\text { 曲 Published online: } 13 \text { Feb } 2018 .
$$

Submit your article to this journal $₫$

Q View related articles $₫$

View Crossmark data ¿ 


\title{
Objectified conformity: working self-objectification increases conforming behavior*
}

\author{
Luca Andrighetto ${ }^{a}$, Cristina Baldissarrib ${ }^{b}$ Alessandro Gabbiadini ${ }^{b}$, Alessandra Sacino ${ }^{a}$, \\ Roberta Rosa Valtortab and Chiara Volpato ${ }^{\mathrm{b}}$
}

aDepartment of Educational Sciences, University of Genoa, Genova, Italy; ${ }^{b}$ Department of Psychology, University of Milano-Bicocca, Milan, Italy

\begin{abstract}
The present work explores whether self-objectification triggered by doing peculiar work activities would increase people's conforming behavior. We conducted an experimental study in which participants ( $N=140$ ) were asked to perform a high objectifying activity (vs. low objectifying activity vs. baseline condition) simulating a real computer job. Afterwards, their levels of self-objectification and conforming behavior were assessed. Results revealed that participants who performed the high objectifying activity self-objectified (i.e., perceived themselves as lacking human mental states) more than the other conditions and, in turn, conformed more to the judgments of unknown similar others. Crucially, increased self-objectification mediated the effects of the high objectifying activity on enhancing conforming behavior. Theoretical and applied implications of these findings are discussed.
\end{abstract}

\section{ARTICLE HISTORY}

Received 11 December 2017 Accepted 6 February 2018

KEYWORDS

Self-objectification; objectifying activity; mental states; conformity

A recent representative survey (Gino, 2016) revealed that almost half of workers regularly feel the need to conform to their own organization's norms and that more than half of them do not question its status quo. This may appear surprising as, especially since after the 2007-2010 Great Recession, conditions within many workplaces have become particularly disheartening (see, e.g., European Observatory of Working Life, 2013). There are many reasons why workers tend to conform and to accept the status quo, including job insecurity (Benach et al., 2014), the pressure that organizations commonly put on employees or, more simply, the epistemic people's need to bolster the status quo, rather than to question it (Jost, Banaji, \& Nosek, 2004; Jost, Becker, Osborne, \& Badaan, 2017).

Through the present work, we aim to demonstrate that work activity per se may represent a further relevant source of conformity. More specifically, our main goal is to show that performing high objectifying work activities leads people to self-objectify and, in turn, to increase their conforming behavior. 


\section{Working objectification}

Objectification is a pervasive phenomenon in the work domain. Perceiving others as mere objects is in fact a powerful cognitive strategy that rationalizes their exploitation or subordination (Volpato, Andrighetto, \& Baldissarri, 2017). Among the different facets of objectification (Nussbaum, 1995), two are especially crucial in working settings: instrumentality - the perception (and treatment) of the target as an instrument that facilitates the completion of the objectifier's personal goals - and denial of humanness - the view of the target as an entity that lacks autonomy and subjectivity.

Objectification of workers became a debated issue with the rise of capitalism and scientific management. For instance, Marx (1844) argued that workers in a capitalistic society are denied the traits that define their humanity and judged exclusively in terms of what they produce. Although these reflections may appear to belong to a past era, the objectification of workers still permeates many workplaces. A recent report $(\mathrm{BBC}, 2013)$ documented the object-like treatment of Amazon 'order-pickers'. Their daily activity is highly repetitive and mostly limited to picking orders from supervisors and finding products in the warehouse. Further, their working pace is entirely imposed by a timer, starting as soon as they get an order. Even though this timer often gives only a few seconds to complete a task, workers must follow it in order to maintain the pace of the deliveries and, more broadly, the productivity of the company.

Despite the relevance of working objectification, this phenomenon has been long investigated in the sexual domain (see Gervais, 2013; Loughnan \& Pacilli, 2014; for recent reviews) and only recently social psychologists have begun to investigate it in the workplace. A growing amount of evidence reveals that objectification in the workplace is triggered by multiple factors, such as the motivation for money (Wang \& Krumhuber, 2017; see also Teng, Chen, Poon, Zhang, \& Jiang, 2016) or asymmetrical power relations between the objectifier and the target (Gruenfeld, Inesi, Magee, \& Galinsky, 2008). Further, objectification may be embodied in the features of the work itself. Specifically, Andrighetto, Baldissarri, and Volpato (2017) revealed that the salience of three core characteristics of work tasks significantly increases the perception of the workers as object-like. These core features are the repetitiveness of movements - continuously performing the same task or set of a few tasks; the fragmentation of the activity - doing a limited task which is only a part of the whole production process; the other-direction of the working pace - performing an activity which is controlled by external sources, such as a conveyor belt or a timer.

Of particular relevance to the present research, Baldissarri, Andrighetto, Gabbiadini, and Volpato (2017) also found that a work activity with these features deeply influences those who perform it. In particular, in a series of laboratory and field studies they found that the primary consequence of doing a manual or computer activity characterized by repetitiveness, fragmentation and other-direction is the workers' self-objectification, that is, self-perception as instrument-like (i.e., instrumentality dimension) and as lacking human mental states (i.e., denial of humanness). Interestingly, their findings showed that selfobjectification is in turn associated with a variety of intrapersonal consequences, including reduced personal well-being (Baldissarri, Andrighetto, \& Volpato, 2017) and decreased belief in having free will (Baldissarri, Andrighetto, \& Volpato, 2017; Baldissarri, Andrighetto, Gabbiadini, et al., 2017). 
The research reported here moves beyond this prior research by investigating a possible interpersonal consequence of working self-objectification, i.e., the tendency to conform to others. In doing so, for the first time in this field, we employed an unobtrusive behavioral measure. In fact, so far, the consequences of working self-objectification have been mainly investigated by using self-report measures, that may have invoked demand characteristics.

\section{Working self-objectification and conformity}

Since the pioneering work of Asch (1956), a great body of literature has documented that individuals tend to be influenced by others' opinions and attitudes. Explicit or implicit influence by others can come from external sources, such as authority, peers, superiors or colleagues, but also from more internal sources (see Cialdini \& Goldstein, 2004 for a review). Although not all conformity is bad, a high degree of conformism may lead to negative consequences in a wide range of domains. In particular, Gino, Kouchaki, and Galinski (2015) observed that in the working domain employees' conformity reduces their engagement with the job, as it increases their feeling of behaving in a way that does not express their true self. Further, employees' conformity shapes their performance over time, by lowering their productivity and innovative behavior which, in turn, can lead to stagnation of the organization (Gino, 2016). From a broader perspective, workers' conformity plausibly fuels their passive acceptance of the status quo and existing working inequalities, undermining their willingness to undertake collective actions and thus hindering progressive societal change (see Kreiner, Ashforth, \& Sluss, 2006).

Recent studies also empirically investigated factors enhancing conformity in the work domain and suggested a link between performing low-status works and the tendency to conform to others. For example, Galinsky, Magee, Gruenfeld, Whitson, and Liljenquist (2008) revealed that people in low-power positions tend to conform more to their peers. Furthermore, Stephens, Markus, and Townsend (2007) documented that working-class people tend to display a normative preference for similarity to others, whereas middle-class people tend to normatively differentiate from others. Consistently Stephens, Fryberg, and Markus (2011) through three experimental studies showed that the working-class participants who reported having limited choice at work were less prone to make individual choices.

In the present work we aim to take a step further by identifying a work antecedent of conformity not yet explored. More specifically, we aimed to empirically verify whether work activity per se may constitute a further relevant source of people's conformity through increased self-objectification. That is, we conceived working self-objectification as the key psychological mechanism explaining the effects of doing an objectifying work activity on increased conformity.

Congruent with previous research (Baldissarri, Andrighetto, \& Volpato, 2017; Baldissarri, Andrighetto, Gabbiadini, et al., 2017), we first assumed that performing repetitive, fragmented and other-directed work activity (i.e., an objectifying activity) would elicit people's self-objectification. In turn, we expected that self-objectification would impact people's conforming behavior. This latter assumption is in line with a broader theoretical perspective on the phenomenon of objectification (Nussbaum, 1995; Zurbriggen, 2013), positing that self-objectified people feel themselves as stripped of peculiar mental states, such as a sense 
of control over their own actions, self-determination and agentic qualities. These are all uniquely human features plausibly linked with the conformity process. Some works have in fact revealed that behaving for oneself, forming one's own opinions rather than following those of others require uniquely human qualities, such as a sense of control over their own actions (Alquist, Ainsworth, \& Baumeister, 2013) or feelings of self-efficacy (Todd, Sheldon, Ira, \& Boris, 2006). Further, our assumption is indirectly supported by empirical research reporting that self-objectification makes people passive and, thus, less inclined to think and behave for oneself. For example, in the work domain Baldissarri and colleagues (2017) showed that working self-objectification negatively affects personal beliefs in having free will. In the sexual domain, Calogero (2013) revealed that self-objectified women are less prone in engaging gender-based social activism. In addition, Saguy, Quinn, Dovidio, and Pratto (2010) demonstrated that when women feel self-objectified they display more passive behavior during social interactions.

Based on these theoretical claims and empirical evidence, we expected that a heightened sense of being self-objectified due to performing high objectifying activities would provide a fertile ground for conformity, by leading people to conform more to opinions provided by unknown others.

\section{The present study}

Our hypotheses were tested through an experimental study in which laypeople performed a computer task that simulated a real work activity in a laboratory setting. This activity was ad hoc created so that in the high objectifying activity (vs. low objectifying activity vs. baseline) the key features conveying working objectification (i.e., repetitiveness, fragmentation and other-direction) were made salient (see Baldissarri, Andrighetto, Gabbiadini, et al., 2017 for a similar procedure). Afterwards, people's self-objectification and conforming behavior were detected. We opted for assessing self-objectification in terms of self-perception as lacking human mental states (Haslam, Kashima, Loughnan, Shi, \& Suitner, 2008) rather than increased self-perceptions as instrument-like, as we reasoned that undermined selfperceptions as characterized by human mental states would better represent the (inhibition of) human factors involved in the process of conformity. Further, conformity was measured through a dot estimation task (Castelli, Vanzetto, Sherman, \& Arcuri, 2001) in which conforming behavior was conceived as the participants' tendency to adhere to previous responses provided by unknown similar others.

\section{Method}

\section{Participants and experimental design}

One-hundred and forty undergraduates (117 females; $\left.M_{\text {age }}=21.55, \mathrm{SD}=2.22\right)$ from a northwestern Italian university participated on a voluntary basis. They were randomly allocated to one of three conditions (high objectifying activity vs. low objectifying activity vs. baseline condition). A post hoc power analysis conducted with $\mathrm{G}^{\star}$ Power 3.1 determined that this sample size would be sufficient to detect a medium-sized effect $\left(f^{2}=.27\right)$ at $80 \%$ power, $p<.05$. 


\section{Procedure and materials}

Participants were examined individually. Upon their arrival in the laboratory, the experimenter informed them that the study was psychology research on new recruiting strategies. After obtaining their informed consent, in the high and low objectifying activity conditions participants were instructed to imagine working for an e-computer shop. For both conditions, the work activity lasted $20 \mathrm{~min}$.

The high objectifying activity was created ad hoc to make particularly salient the three key work features eliciting self-objectification (Baldissarri, Andrighetto, Gabbiadini, et al., 2017), i.e., fragmentation, repetitiveness and other-direction of the activity. Fragmentation was made salient by informing participants that they had to perform a part of the sale process: they were asked to read the customers' orders appearing at the top of the screen and then to select the products corresponding to the customer's budget. They repeated this action 40 times. Further, their working pace was directed by a timer that appeared on the screen and that warned them that they had $30 \mathrm{~s}$ to complete each order.

The low objectifying activity had a similar scope but was created to be a less fragmented, varied, and self-directed activity. Participants were instructed that their task was to manage the whole sale process. That is, they were asked to perform different actions throughout the 20 min of the activity, such as compiling the package, replying to customers' personalized requests and organizing appointments with them. Further, the participants were not given any specific indications about the working pace. ${ }^{1}$

In the baseline condition, participants came into the laboratory for assessment without performing any activity.

Afterwards, participants completed a paradigm adapted by Castelli and colleagues (2001) that assessed their conforming behavior. It was presented as a dot estimation task unrelated to the main study and designed to validate some stimuli for a future cognitive study. Participants were presented with 10 trials $(\alpha=.91)$. For each trial, a slide with a series of letter "as" (see Figure 1 for an example) appeared for $5 \mathrm{~s}$ on a 17" monitor with a resolution of $1280 \times 1024$ pixels. A fictitious estimate of the number of letters was presented at the top of the screen. Participants were told this number was the average estimate given by the previous participants. They were then asked to provide their estimation. For all participants,

Average of previous estimates: 152

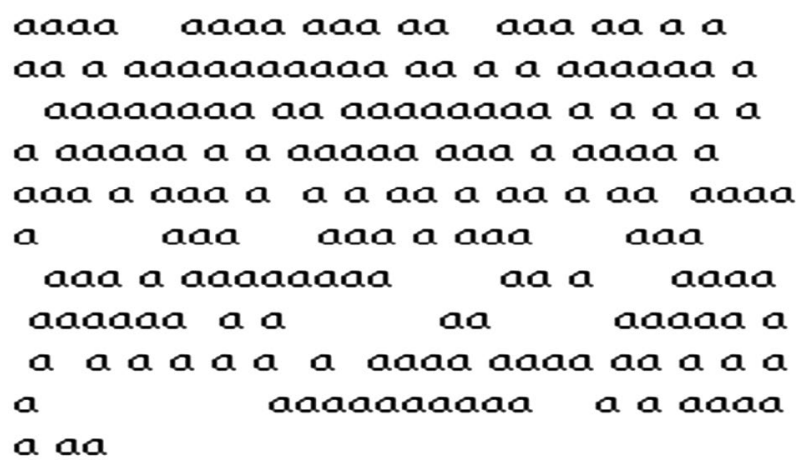

Figure 1. An example of a slide used in the dot estimation task. 
the images with the "a's" and the fictitious estimates were the same and presented in the same order.

After this task, participants' self-objectification was assessed through the Self-Mental State Attribution task (SMSA; Baldissarri, Andrighetto, \& Volpato, 2014; see also Haslam et al., 2008). Participants were asked to rate the degree to which they were able to experience 20 human mental states $(\alpha=.96)$ on a 7 -point scale $(1=$ not at all; $7=$ very much $)$ during the computer activity (high objectifying and low objectifying conditions) or at that particular moment (baseline condition). Mental states included perceptions (e.g., seeing), emotions (e.g., admiration, fear), thoughts (e.g., imagining), wishes (attraction) and intentions (e.g., planning). Then, participants in the activity conditions completed three manipulation check items in which they judged the extent to which they perceived the computer activity as repetitive, fragmented and other-directed on a 7 -point scale $(1=$ not at all; $7=$ very $m u c h)$.

Finally, participants were asked to provide sociodemographic data, probed for suspicion, and thoroughly debriefed.

\section{Results}

\section{Exclusion criteria for participants}

Four participants were excluded because they showed suspicion concerning the conformity measure, one because a computer failure occurred during the conformity measure, two because the Mahalanobis distance statistic revealed that they were multivariate outliers. The final sample considered for the analyses was of 133 participants.

\section{Preliminary analyses}

In order to verify whether participants in the high objectifying condition indeed perceived the activity differently than those in the low objectifying condition a MANOVA was conducted. Data analysis showed a main effect of the condition, $\lambda=.63, F(3,84)=16.44, p<.001$, $\eta_{p}^{2}=.37$ : participants who were assigned to the high objectifying activity perceived it as more fragmented $(M=5.09, \mathrm{SD}=1.38)$, repetitive $(M=6.07, \mathrm{SD}=1.14)$ and other-directed $(M=5.28, \mathrm{SD}=1.38)$ than participants assigned to the low objectifying activity (respectively: $M=4.50, \mathrm{SD}=1.22 ; M=4.17, \mathrm{SD}=1.41 ; M=4.60, \mathrm{SD}=1.58 ;$ all $F_{s}(1,86) \geq 4.45, p_{s<} .04$, $\left.\eta_{p s}^{2} \geq .05\right)$. These results suggested that our manipulation was successful.

For the SMSA measure the 20 items were collapsed into a single index so lower scores indicated a lower self-attribution of mental states and, thus, higher levels of self-objectification. Conformity was operationalized as the distance between the provided anchors and the participants' actual judgments. In particular, to reduce the variance within subjects, for each trial we divided the absolute value of the difference between the fictitious estimate and the participant's estimate by the participant's estimation (see Wyer, 1966). We then collapsed the calculated values for the 10 trials into a single conformism index, so a lower score corresponded with a smaller distance between the fictitious estimate and the participant's estimation and, thus, higher conformism. A bivariate correlation analysis showed that the SMSA measure $(M=3.97, \mathrm{SD}=1.31)$ and the conformism index $(M=.84, \mathrm{SD}=.72)$ were correlated $(r=.26, p=.003)$ : lower self-attribution of mental states corresponded with a higher tendency for a participant to conform to others. 


\section{Main analyses}

We first conducted two univariate ANOVAs to verify the effects of the experimental condition (high objectifying activity vs. low objectifying activity vs. baseline condition) on participants' self-objectification and conforming behavior (see Table 1). Regarding selfobjectification, analyses revealed a main effect of the condition: $F(2,132)=165.74, p<.001$, $\eta_{p s}^{2}=.72$. Bonferroni-adjusted comparisons revealed that participants in the high objectifying activity self-attributed mental states at a lower rate than participants in the low objectifying activity, $p=.003$, and participants in the baseline, $p<.001$. Further, participants in the low objectifying activity self-objectified more than participants in the baseline condition, $p<.001$. Regarding conforming behavior, analyses showed a main effect of the condition: $F(2,132)=3.29, p=.040, \eta_{p s}^{2}=.05$. Bonferroni-adjusted comparisons revealed that participants who performed the high objectifying activity displayed greater conforming behavior than participants in the baseline condition, $p=.036$, but not greater than those in the low objectifying activity, $p=.404$. Instead, conforming behavior for participants' in the low objectifying activity and in baseline condition were not different, $p=.907$.

We then ran a mediational analysis using the PROCESS macro (Hayes, 2018; Model 4) with 5000 bootstrapping samples to verify the mediational role of the self-objectification on the relation between high objectifying activity (vs. low objectifying activity vs. baseline condition) and conforming behavior. Moreover, since the independent variable was multicategorical, we followed the recommendations of Hayes and Preacher (2014) and used indicator coding. The high objectifying activity condition was coded as the reference condition and was compared to the low objectifying activity (D1) and baseline condition (D2) separately. As shown in Figure 2, the effects of high objectifying activity vs. low objectifying activity (D1) and of high objectifying activity vs. baseline condition (D2) on SMSA were significant $(b=.50, \mathrm{SE}=.15, t(2,130)=3.38, p=.001$ and $b=2.53, \mathrm{SE}=.15, t(2,130)=$ $17.28, p<.001$, respectively), indicating that performing an high objectifying activity (vs. low objectifying activity and vs. baseline condition) led to a decrease in self-attribution of mental states. Further, SMSA was associated with the conforming behavior index $(b=.18$, $\mathrm{SE}=.88, t(3,129)=2.00, p=.048)$, indicating that lower self-attribution of mental states by participants was linked to a greater tendency to conform to others. In addition, the effects of D1 and D2 on conforming behavior were both not significant when controlling for SMSA $(b=.14, \mathrm{SE}=.16, t(3,129)=.89, p=.384$ for $\mathrm{D} 1, b=-.07, \mathrm{SE}=.27, t(3,129)=-.25, p=.803$ for D2). Most importantly and supporting our mediational hypothesis, the indirect effects of D1 and D2 on conforming behavior through SMSA were significant $\left(a^{\star} b=.09,95 \% \mathrm{CI}\right.$ $[.011, .227]$ and $a^{\star} b=.45,95 \%$ CI $[.122, .852]$, respectively).$^{2}$

Table 1. Mean ratings of self-mental state attribution and conforming behavior as a function of the activity manipulation

\begin{tabular}{lccc}
\hline & \multicolumn{3}{c}{ Conditions } \\
\cline { 2 - 4 } Variables & High objectifying & Low objectifying & Baseline \\
\hline SMSA & $2.95_{\mathrm{a}}(.76)$ & $3.45_{\mathrm{b}}(.77)$ & $5.48_{\mathrm{c}}(.54)$ \\
Conforming behavior & $.64_{\mathrm{a}}(.60)$ & $.87_{\mathrm{ab}}(.74)$ & $1.02_{\mathrm{b}}(.78)$ \\
\hline
\end{tabular}

Notes: Means with different subscripts in the same row differ significantly, $p<.05$. Standard deviations are provided in parentheses. SMSA = Mental State Attribution. 


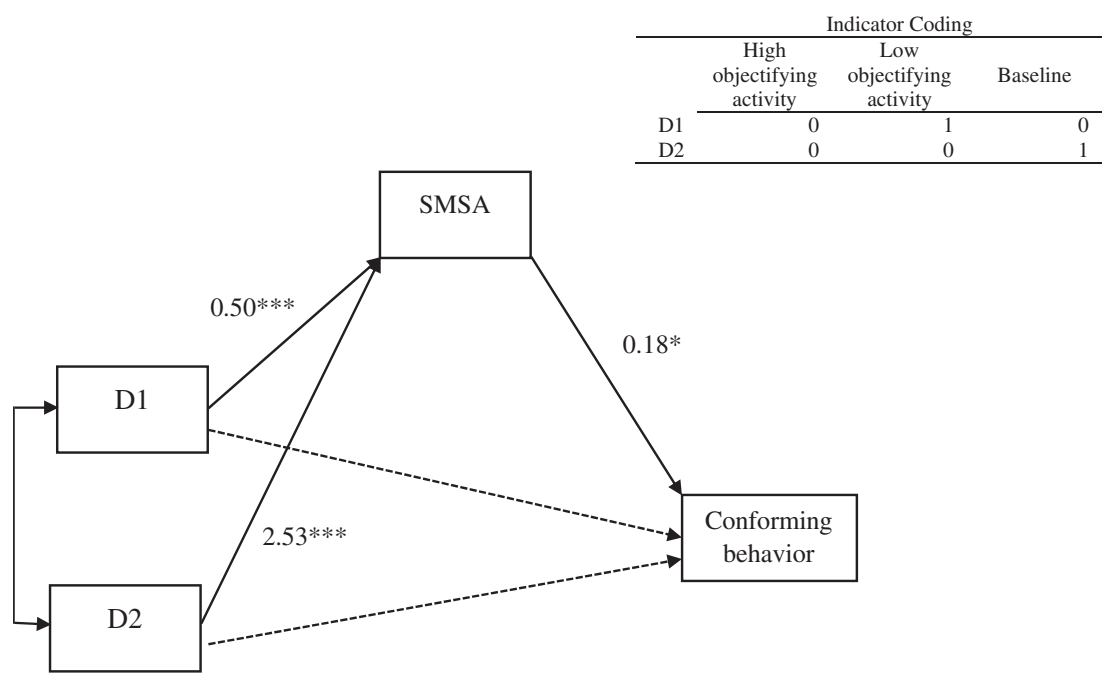

Figure 2. Mediational model testing the indirect effects of high objectifying activity (vs. low objectifying activity vs. baseline condition) on conforming behavior through self-mental state attributions. Note: The reported values are unstandardized beta coefficients. SMSA $=$ Self Mental State Attribution. ${ }^{*} p \leq .05 .{ }^{* * *} p \leq .001$.

\section{General discussion}

Our findings provide a first evidence that performing certain work activities affects conforming behavior. Indeed, performing a working activity highly repetitive, fragmented and other-directed (i.e., a high objectifying activity) increases self-objectification, by triggering an internal state in which people perceive themselves as lacking human-like mental states, such as the capacity to plan, intend, or feel basic emotions. In turn, this increased perception of being mindless increases conforming behavior, by making the individuals more prone to follow the opinions of others, rather than thinking for themselves. With regard to the causal link between self-objectification and increased conforming behavior, it is noteworthy that the alternative model that we ruled out (see Endnote 2) revealed that when the high objectifying condition was compared with the baseline condition (D1) the conformity behavior index partially mediated the relationship between performing a high objectifying activity and increased self-objectification. From a theoretical perspective and in the light of this finding, we cannot exclude a bidirectional relationship between self-objectification and conforming behavior. Thus, we speculate that the feeling of conforming to others' behavior can also strengthen the perception of being similar to an object, by creating a downward spiral in which conformity and self-objectification would influence each other.

It is also noteworthy the fact that the low objectifying condition conveyed levels of self-objectification significantly higher than the baseline condition (for similar results see Baldissarri, Andrighetto, Gabbiadini, et al., 2017; Study 3). This finding may support the idea that in most jobs (or at least in computer based ones) work activities cannot be categorized in dichotomous terms as objectifying or non-objectifying activities. Rather, working self-objectification plausibly evolves on a continuum which increases along with the salience of the objectifying features: the more the activity is characterized by them, the more people self-objectify. Therefore, doing any computer-related work activity in a laboratory situation would be perceived somewhat objectifying and consequently elicits self-objectification, 
at least when compared with a baseline condition that do not consist of any activity. For example, the time limit (i.e., $20 \mathrm{~min}$ ) that was imposed by the experimenter also in the non-objectifying condition may have elicited a perception of other-direction.

We believe that the present research meaningfully contributes to the growing body of research exploring dehumanizing perceptions in the work domain. Indeed, the initial research in this field mainly focused on intrapersonal outcomes of these perceptions (Auzoult \& Personnaz, 2016; Baldissarri et al., 2014; Baldissarri, Andrighetto, \& Volpato, 2017; Baldissarri, Andrighetto, Gabbiadini, et al., 2017; Caesens, Stinglhamber, Demoulin, \& De Wilde, 2017). In this work, we focused on the tendency to conform to others, a more interpersonal consequence of self-objectification in the workplace. Showing that performing certain work activities leads people to more easily accept the opinions of others may help explain contingent societal phenomena, especially concerning low-status workers. Although we do not claim that objectifying activities concern exclusively low-status works, features such as repetitiveness, other-direction or the impossibility to make choices are undoubtedly more common in lowthan high-status occupations. Thus, we believe that increased conformity because of working self-objectification is more likely to occur among low-status workers. Consistent with this reasoning, our results may shed further light on the reasons why low-status workers so rarely take collective actions aimed to change the status quo (see e.g., Jost et al., 2017), but rather tend to accept their working condition and follow the social norms of their organizations, even when these are clearly unfair. At the same time, we do not argue that higher tendencies to conform to others due to certain work activities are the only or even the primary explanation of these missing collective actions. Job insecurity, the pressures that the organizations put on their workers, and the tendency to justify the social and economic status quo on which people depend (Jost \& van der Toorn, 2012) undoubtedly concur to explain this phenomenon.

The present findings may have also important implications for organizations. Indeed, organizations may suffer from high levels of employees' conformity, as they commonly lead to less commitment to the workplace, productivity and innovation. Various and more challenging activities could enhance employees' engagement and their motivation to innovate. For example, Staats and Gino (2012) through an empirical analysis reported that bankers who were day by day charged with diverse tasks were more motivated and thus more productive. Further, job rotation, on the one hand, would broaden the workers' skill set, on the other hand, it could enhance workers' feelings of doing a more complete, less fragmented and consequently less objectifying job. In this regard, an interesting neuroscience study (Zald et al., 2008) revealed that trying novel actions increases the release of dopamine, a neurotransmitter that helps people remain motivated. However, promoting the variety of activities may not be enough to reduce self-objectification and, thus, conformity in the workplaces. Another interesting strategy which is pursued in some virtuous companies is that of constantly allowing employees to make decisions (see Ton, 2012). Although they often are small decisions and assisted by supervisors, they may contribute to the workers' active involvement in the organization and, thus, make them less inclined to self-objectify and passively follow the others' opinions.

\section{Limitations and future directions}

The present research could be advanced in a number of ways that would address its methodological limitations and shed light on untested psychological mechanisms at play. 
From a methodological perspective, we first acknowledge that this is a single study. Although the power of our sample size gives us confidence in the robustness of our findings, further studies are needed to replicate them, by considering real workers or employing different paradigms and measures. In particular, to increase the generalizability of our findings, future studies should consider different work activities which do not imply PC tasks and employ baseline conditions which imply a non-working activity.

Second, as with many laboratory procedures, the behavior measured had low personal significance to participants, as it consisted of a dot estimation task. It is important to verify whether the same effects emerge also in cases involving strong personal opinions and values.

Third, our study does not allow us to ascertain which features (e.g., sense of control, self-determination) inhibited by the state of self-objectification are more (or less) relevant in determining the increased tendency to conform to others. Future studies are necessary for assessing the separate impact of the uniquely human abilities involved in this process. Partially linked with this issue, we do not exclude the fact that alternative mediators more tightly linked with people's cognitive resources (e.g., ego depletion, cognitive load) could contribute with self-objectification to explain the relationship between performing objectifying activities and conforming behavior.

Fourth, we reason that a more exhaustive picture will be obtained through future studies that will empirically investigate which further organizational factors (e.g., job insecurity, organizational pressure) can affect conforming behavior.

Finally, we do not maintain that self-objectification is the only form of dehumanization that enters into play to explain our effects. It would be particularly interesting to verify whether mechanistic dehumanization (see e.g., Haslam \& Loughnan, 2014), a further form of dehumanization that emerges in working settings (Caesens et al., 2017), could also play a mediator role in explaining our effects.

\section{Conclusions}

Although workers' rights have progressed in most western countries, the object-like treatment of workers still remains a problem in many workplaces, especially after the Great Recession. A burgeoning literature is showing that this type of treatment typically triggers workers' self-objectification, which in turn negatively affects their psychological state. In the present study, we identified an unexplored outcome of this process, the tendency to conform to others. We believe that this outcome does not only affect the workers' way of living. Over time, organizations pay a price for this conformism, as chances for innovation decrease where nonconformist thoughts are inhibited. Thus, implementing labour policies that prevent the rise of self-objectification and its relative consequences in the workplace may not only improve the psychological state of workers but also provide broader benefits for organizations and the social system.

\section{Notes}

1. Additional procedure details about the experimental paradigm are reported in Baldissarri, Andrighetto, Gabbiadini, et al. (2017) paper. Supplementary material from the same paper describes a pilot study that tested the validity of these ad hoc created activities.

2. We also tested an alternative model in which we considered participants' conforming behavior as the mediator and SMSA as the outcome variable. Data analyses revealed that the effects of 
the objectifying activity vs. baseline condition (D2) on conforming behavior were significant $(b=-.38, \mathrm{SE}=.15, t(2,130)=-2.54, p=.012)$, whereas the effects of objectifying activity vs. non-objectifying activity (D1) were not $(b=-.15, \mathrm{SE}=.15, t(2,130)=-.99, p=.324)$. Further, the direct effects of D1 and D2 on SMSA remained significant even when entered together with conforming behavior $(b=-2.00, \mathrm{SE}=.15, t(3,129)=-13.48, p<.001$ for $\mathrm{D} 1$; $b=-2.47, \mathrm{SE}=.15, t(3,129)=-16.62, p<.001$ for D2) and the indirect effects from the predictors variable via conforming behavior on SMSA were significant for D2 $\left(a^{*} b=-.06\right.$, $95 \%$ CI $[-.179,-.007])$, but not for D1 $\left(a^{\star} b=-.03,95 \%\right.$ CI $\left.[-.128, .020]\right)$.

\section{Acknowledgments}

We thank Laura Frola, Clelia Petrolini and Elena Porcile for assistance with data collection.

\section{Disclosure statement}

No potential conflict of interest was reported by the authors.

\section{References}

Alquist, J.L., Ainsworth, S.E., \& Baumeister, R.F. (2013). Determined to conform: Disbelief in free will increases conformity. Journal of Experimental Social Psychology, 49, 80-86.

Andrighetto, L., Baldissarri, C., \& Volpato, C. (2017). (Still) modern times: Objectification at work. European Journal of Social Psychology, 47, 25-35.

Asch, S.E. (1956). Studies of independence and conformity: 1. A minority of one against a unanimous majority. Psychological Monographs, 70, whole issue.

Auzoult, L., \& Personnaz, B. (2016). The role of organizational culture and self-consciousness in selfobjectification in the workplace. TPM, Testing, Psychometrics, Methodology in Applied Psychology, 23, 1-14.

Baldissarri, C., Andrighetto, L., Gabbiadini, A., \& Volpato, C. (2017). Work and freedom: Working self-objectification and belief in personal free will. British Journal of Social Psychology, 56, 250-269.

Baldissarri, C., Andrighetto, L., \& Volpato, C. (2014). When work does not ennoble man: Psychological consequences of working objectification. TPM, Testing, Psychometrics, Methodology in Applied Psychology, 21, 327-339.

Baldissarri, C., Andrighetto, L., \& Volpato, C. (2017). Feeling like an object: Antecedents and consequences of self-objectification in real-work settings. Manuscript under review.

BBC. (2013, November 23). The truth behind the click. Retrieved from www.bbc.co.uk/programmes/ b03k5kzp

Benach, J., Vives, A., Amable, M., Vanroelen, C., Tarafa, G., \& Muntaner, C. (2014). Precarious employment: Understanding an emerging social determinant of health. Annual Review of Public Health, 35, 229-253.

Caesens, G., Stinglhamber, F., Demoulin, S., \& De Wilde, M. (2017). Perceived organizational support and employees' well-being: The mediating role of organizational dehumanization. European Journal of Work and Organizational Psychology, Advance online publication.

Calogero, R.M. (2013). Objects don't object: Evidence that self-objectification disrupts women's social activism. Psychological Science, 24, 312-318.

Castelli, L., Vanzetto, K., Sherman, J., \& Arcuri, L. (2001). The explicit and implicit perception of ingroup members who use stereotypes: Blatant rejection but subtle conformity. Journal of Experimental Social Psychology, 37, 419-426.

Cialdini, R.B., \& Goldstein, N.J. (2004). Social influence: Compliance and conformity. Annual Review of Psychology, 55, 591-621.

European Observatory of Working Life. (2013). Impact of the crisis on working conditions in Europe. Retrieved from https://www.eurofound.europa.eu/observatories/eurwork 
Galinsky, A.D., Magee, J.C., Gruenfeld, D.H., Whitson, J.A., \& Liljenquist, K.A. (2008). Power reduces the press of the situation: Implications for creativity, conformity, and dissonance. Journal of Personality and Social Psychology, 95, 1450-1466.

Gervais, S. (2013). Objectification and (de)humanization: The 60th Nebraska symposium on motivation. New York, NY: Springer.

Gino, F. (2016). Let your workers rebel. Harvard Business Review. Retrieved from http://www.hbs. edu/faculty/Publication Files

Gino, F., Kouchaki, M., \& Galinski, A.D. (2015). The moral virtue of authenticity: How inauthenticity produces feelings of immorality and impurity. Psychological Science, 26, 983-996.

Gruenfeld, D.H., Inesi, M.E., Magee, J.C., \& Galinsky, A.D. (2008). Power and the objectification of social targets. Journal of Personality and Social Psychology, 95, 111-127.

Haslam, N., Kashima, Y., Loughnan, S., Shi, J., \& Suitner, C. (2008). Subhuman, inhuman, and superhuman: Contrasting humans with nonhumans in three cultures. Social Cognition, 26, 248-258.

Haslam, N., \& Loughnan, S. (2014). Dehumanization and infrahumanization. Annual Review of Psychology, 65, 399-423.

Hayes, A.F. (2018). Introduction to mediation, moderation, and conditional process analysis (2nd ed.). New York, NY: The Guilford Press.

Hayes, A.F., \& Preacher, K.J. (2014). Statistical mediation analysis with a multicategorical independent variable. British Journal of Mathematical \& Statistical Psychology, 67, 451-470.

Jost, J.T., Banaji, M.R., \& Nosek, B.A. (2004). A decade of system justification theory: Accumulated evidence of conscious and unconscious bolstering of the status quo. Political Psychology, 25, 881919.

Jost, J.T., Becker, J., Osborne, D., \& Badaan, V. (2017). Missing in (Collective) action: Ideology, system justification, and the motivational antecedents of two types of protest behaviour. Current Directions in Psychological Science, 26, 99-108.

Kreiner, G.E., Ashforth, B.E., \& Sluss, D.M. (2006). Identity dynamics in occupational dirty work: Integrating social identity and system justification perspectives. Organization Science, 17, 619-636.

Loughnan, S., \& Pacilli, G. (2014). Seeing (and treating) others as sexual objects: Toward a more complete mapping of sexual objectification. Testing, Psychometrics, Methodology in Applied Psychology, 21, 309-325.

Marx, K. (1844). Economic and philosophic manuscripts of 1844. (M. Milligan, trans., p. 2012). Mineola, NY: Dover Publications.

Nussbaum, M. (1995). Objectification. Philosophy and Public Affairs, 24, 249-291.

Saguy, T., Quinn, D.M., Dovidio, J.F., \& Pratto, F. (2010). Interacting like a body objectification can lead women to narrow their presence in social interactions. Psychological Science, 21, 178-182.

Staats, B.R., \& Gino, F. (2012). Specialization and variety in repetitive tasks: Evidence from a Japanese bank. Management Science, 58, 1141-1159.

Stephens, N.M., Fryberg, S.A., \& Markus, H.R. (2011). When choice does not equal freedom: A sociocultural analysis of agency in working-class American contexts. Social Psychological and Personality Science, 2, 33-41.

Stephens, N.M., Markus, H.R., \& Townsend, S.S. (2007). Choice as an act of meaning: The case of social class. Journal of Personality and Social Psychology, 93, 814-830.

Teng, F., Chen, Z., Poon, K.T., Zhang, D., \& Jiang, Y. (2016). Money and relationships: When and why thinking about money leads people to approach others. Organizational Behaviour and Human Decision Processes, 137, 58-70.

Todd, L., Sheldon, A., Ira, F., \& Boris, B. (2006). Self-efficacy and independence from social influence: Discovery of an efficacy-difficulty effect. Social Influence, 1, 58-80.

Ton, Z. (2012). Why 'good jobs' are good for retailers. Harvard Business Review. Retrieved from https://hbr.org/2012/01/

Jost, .J.T., \& van der Toorn, .J. (2012). System justification theory. In P.A.M. van Lange, A.W. Kruglanski, \& E.T. Higgins (Eds.), Handbook of theories of social psychology, Vol. 2 (pp. 313-343). London, UK: Sage.

Volpato, C., Andrighetto, L., \& Baldissarri, C. (2017). Perceptions of low-status workers and the maintenance of the social class status quo. Journal of Social Issues, 73, 192-210. 
Wang, X., \& Krumhuber, E. (2017). The love of money results in objectification. British Journal of Social Psychology, 56, 354-372.

Wyer, R.S. (1966). Effects of incentive to perform well, group attraction, and group acceptance on conformity in a judgmental task. Journal of Personality and Social Psychology, 1, 21-26.

Zald, D.H., Cowan, R.L., Riccardi, P., Baldwin, R.M., Ansari, M.S., Li, R., ... Kessler, R.M. (2008). Midbrain dopamine receptor availability is inversely associated with novelty-seeking traits in humans. The Journal of Neuroscience, 28, 14372-14378.

Zurbriggen, E. (2013). Objectification, self-objectification, and societal change. Journal of Social and Political Psychology, 1, 188-215. 